\title{
Progressive severe dyspnea and hypoxia due to primary thyroid lymphoma: steroid administration may be life- saving
}

\author{
Derya Köseoğlu ${ }^{1}$ Alper Çağrı Karcı ${ }^{1}$, Aydın Acar ${ }^{2}$, Elvan Evrim Tuna², Dilek Berker ${ }^{1}$
}

\begin{abstract}
Primary Thyroid lymphoma is an uncommon malignancy, which can rarely cause severe dyspnea. Its commonly difficultly diagnosed and rapid diagnosis and management may be lifesaving. Here we report a case presented with sudden thyroid growth and severe dyspnea, who was diagnosed as primary thyroid lymphoma. A 70-year-old woman applied with fatigue, rapidly enlarged goitre and severe progressive dyspnea. She had severe hypoxemia with an artery oxygen saturation of $59.2 \%$ and arterial PO2 of $33.9 \mathrm{mmHg}$. The ultrasound of the neck showed an enlarged thyroid gland with a mass in the left lobe. After admission to the hospital her dyspnea worsened and oxygen and bronchodilator treatment gave no benefit. IV methylprednisolone was administered, and the patient's symptoms partially improved. Meanwhile in spite of supportive therapy, the patient underwent urgent surgery for acute airway obstruction and thyroidectomy was performed. After surgery the diagnosis was high grade diffuse large B-cell nonHodgkin's lymphoma.
\end{abstract}

Keywords: goitre, primary thyroid lymphoma, steroid

\section{INTRODUCTION}

Thyroid nodules are common features and may be present in as much as $65 \%$ of the population (1), with a slow growth pattern even if they are malign nodules (2). When sudden rapid thyroid nodule growth occurs; hemorrhage into a benign or malign nodule, differentiating into anaplastic thyroid carcinoma, metastatic cancer and thyroid lymphoma should be suspected $(3,4)$. Primary thyroid lymphoma is an uncommon malignancy, which comprises $0.6-5 \%$ of all thyroid cancers and less than $2 \%$ of extranodal lymphomas $(5,6)$. Its incidence was found to be $2.06 \times 10^{-6}$ cases per year, with a female predominance (7). The most frequent presenting symptoms are rapidly enlarging neck mass, hoarseness, stridor or dyspnea and dysphagia (6-8). About one of three patients are hypothyroid at presentation $(7,8)$. In this report, we present a case of primary thyroid lymphoma presenting with dyspnea.

\section{CASE REPORT}

A 70-year-old woman applied to the emergency department with fatigue and severe progressive dyspnea. She had no medical history or prior medication, except operation for avascular necrosis of the humeral head. She defined goitre for about 6 months, which enlarged rapidly for the last month. Progressive dyspnea and stridor were present for 4 days, which had worsened in the last 12 hours. Physical examination revealed an enlarged thyroid gland with palpable mass about $7 \mathrm{~cm}$ in the left lobe and also there were palpable masses of about $1.5-2 \mathrm{~cm}$ along both cervical areas. She had tachypnea with 30 breaths per minute with normal blood pressure and had no fewer. Cardiovascular examinations showed normal findings, on lung examination bilaterally suppressed breath sounds were detected.

The artery oxygen saturation was $59.2 \%$ and the arterial PO2 was detected as $33.9 \mathrm{mmHg}$, despite an oxygen supplement of $2 \mathrm{lt} / \mathrm{min}$. Ultrasound of the neck showed an enlarged thyroid gland with the right lobe measuring

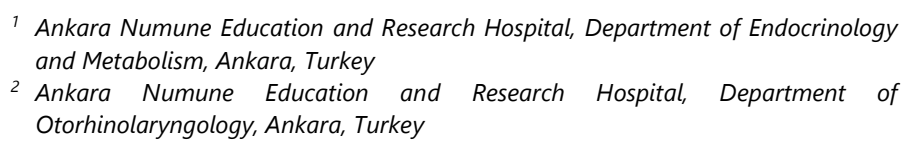

Received: 6 May 2018, Accepted: 6 Aug 2018
Correspondence: Derya Köseoğlu

Ankara Numune Education and Research Hospital, Department of Endocrinology and Metabolism, Ankara, Turkey

E-mail: drderyaksgl@gmail.com

(C) 2018 by the authors; licensee Modestum Ltd., UK. This article is an open access article distributed under the terms and conditions of the Creative Commons Attribution License (http://creativecommons.org/licenses/by/4.0/). 


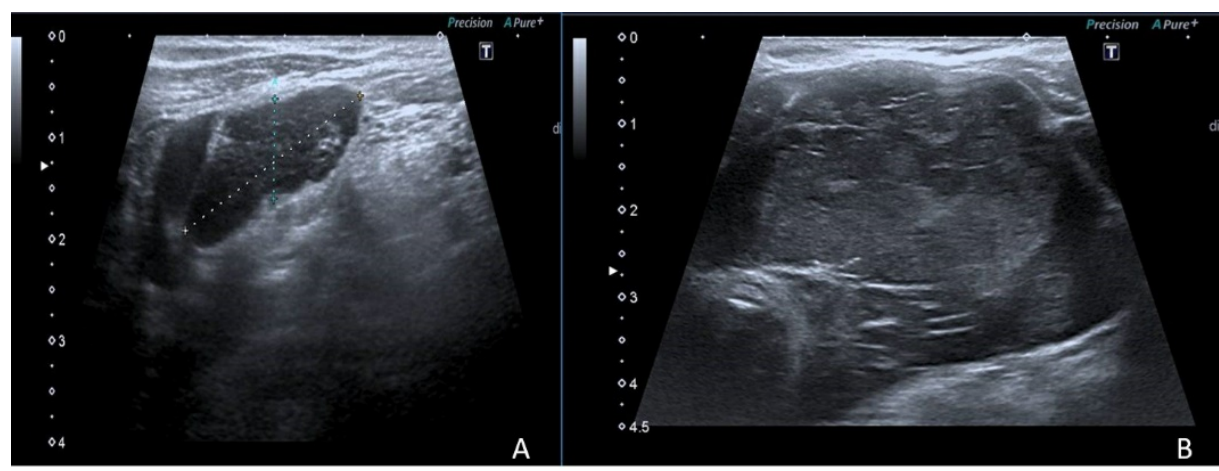

Figure 1: Ultrasonography of the Thyroid gland. Longitudinal (1.A) and tranverse (1.B) view of the mass

$16 \times 17 \times 70 \mathrm{~mm}$ and the left lobe measuring $40 \times 70 \times 80 \mathrm{~mm}$ with a mass of $7 \mathrm{~cm}$ in largest diameter in the left lobe which was irregularly shaped, heterogeneous and hypoechoic (Figure 1). Also the mass was extending to the left lateral trachea wall and to the right thyroid lobe above isthmus. On the right side a $2 \mathrm{~cm}$ lesion was observed that was extending to the right lateral wall of trachea which was suspected as invasion.

Her thyroid function tests were as follows: Thyroid stimulating hormone (TSH):30.89 $\mu$ IU/L (0.27-4.02), free triiodothyronine (FT3): $1.84 \mathrm{pg} / \mathrm{mL}$ (2-4.4), free thyroxine (FT4): $0.71 \mathrm{ng} / \mathrm{L}$ (0.93-1.7). Anti-thyroglobulin antibody and anti-thyroid peroxidase were positive and levothyroxine treatment was started. There was tracheal deviation to the right side with no signs of pulmonary oedema or pulmonary infiltrates on chest $x$ ray. Meanwhile flexible fiberoptic laryngoscopy was performed and left vocal cord palsy and compression to subglottic area from left side were detected. After admission her dyspnea worsened and oxygen and bronchodilator treatment gave no benefit. IV methylprednisolone was administered, and the patient's symptoms partially improved, the arterial oxygen saturation rose to $90 \%$ and the arterial $\mathrm{PO}_{2}$ was detected as $68 \mathrm{mmHg}$. To evaluate the compression a computed tomography scan of the neck was performed and the thyroid mass with compression of the trachea from the anterior, posterior and left sides was detected. The mass invaded the esophagus, the subglottic area and the prevertebral soft tissue. Also mediastinal lymph nodes, $2 \mathrm{~cm}$ in length were detected. Meanwhile fine needle aspiration (FNA) biopsy was performed. The biopsy specimen contained polymorphic lymphoid cells, which were compatible with lymphocytic thyroiditis. A second FNA biopsy with flow cytometry and immunohistochemistry was planned for diagnosis, but in spite of supportive therapy, the patient underwent urgent surgery for acute airway obstruction and thyroidectomy was performed. This approach was also useful for precise diagnosis and debulking.

In the surgery the extension of the mass to the posterior, anterior and left sides of the trachea was detected and also the mass was invading into the tracheal lumen from the right side. Because of this involvement tracheostomy was added to the surgical procedure. The mass was identified as high grade diffuse large B-cell non-Hodgkin's lymphoma with positive immunostaining for CD20, BCL-2 and BCL-6. After thyroidectomy 6 cures of chemotherapy (rituximab, cyclophosphamide, adriamycin, vincristine and prednisone: R-CHOP) has been given till now. After chemotherapy FDGPET/CT scan showed no pathological FDG uptake. She is well now and has no complaints.

\section{DISCUSSION}

Here we present a patient with severe progressive dyspnea and hypoxia, who benefited from methylprednisolone at short-term period and was then treated with surgery and chemotherapy. Primary thyroid lymphoma is a very uncommon malignancy (5-7), frequently presenting with rapidly enlarging neck mass, hoarseness, dyspnea and dysphagia (6-8). Dyspnea is seen in 55-65\% of patient with primary thyroid lymphoma $(7,8)$, but presenting to the emergency department with progressive respiratory distress due to thyroid lymphoma is rare (4).

Diagnosis is often established by FNA, open biopsy and/or surgical intervention. FNA is an effective method in the management of thyroid nodules. However, its role in the diagnosis of primary thyroid lymphoma is limited (4, 8). In a recent retrospective analysis of 64 thyroid lymphoma patients at a tertiary care center, 50\% of patients had FNA as the initial part of the diagnostic workup, and of these only $28 \%$ of patients who underwent FNA were pointed towards the diagnosis of lymphoma (9). In another series 15 patients with thyroid lymphoma had FNA, and 5 patients (34\%) had a FNA cytology outcome as "suggestive of lymphoid malignancy" (8). Most thyroid lymphomas derive from a B-cell origin, and diffuse large B-cell lymphoma is the most common histology with a proportion of up to 87.5\% (9). Our patients FNA 
also showed not the diagnosis of thyroid lymphoma, and the diagnosis could be made as diffuse large B-cell lymphoma after thyroidectomy.

Because the patient had severe dyspnea and hypoxia, methylprednisolone was admitted and a partial clinical response was achieved. Similar to our case, Eng et al. reported 2 patients with enlarging thyroid nodules, which were ultimately diagnosed as thyroid lymphoma (4). The patients had acute respiratory compromise in the absence of tracheal compression. Symptoms rapidly improved with steroid administration (4). The difference of the present case was that the patient had tracheal compression on computed tomography, but the steroid admission was performed before computed tomography application. Because of acute airway obstruction and the need for precise diagnosis, total thyroidectomy and tracheostomy was performed. After thyroidectomy a rituximab-including combined treatment (RCHOP) was used, which had been shown to be effective in treating thyroid diffuse large B-cell non-Hodgkin's lymphoma in elderly patients (9).

In conclusion, primary thyroid lymphoma may present with severe dyspnea, and patients with rapidly enlarging neck mass and dyspnea should be evaluated for primary thyroid lymphoma. Prompt administration of steroid therapy may be effective for improving respiratory symptoms.

\section{REFERENCES}

1. Dean DS, Gharib H. Epidemiology of thyroid nodules. Best Pract Res Clin Endocrinol Metab. 2008;22(6):901-11. https://doi.org/10.1016/j.beem.2008.09.019 PMid:19041821

2. Asanuma K, Kobayashi S, Shingu K, Hama Y, Yokoyama S, Fujimori M, et al. The rate of tumour growth does not distinguish between malignant and benign thyroid nodules. Eur J Surg. 2001;167(2):102-5. https://doi.org/10.1080/110241501750070538 PMid:11266247

3. Lee JK, Lee $\mathrm{DH}$, Cho SW, Lim SC. Acute airway obstruction by spontaneous hemorrhage into thyroid nodule. Indian J Otolaryngol Head Neck Surg. 2011;63(4):387-9. https://doi.org/10.1007/s12070-011-0223-9 PMid:23024949 PMCid:PMC3227835

4. Eng OS, Lesniak S, Davidov T, Trooskin SZ. Diagnosing thyroid lymphoma: steroid administration may result in rapid improvement of dyspnea: a report of two cases. Int J Endocrinol Metab. 2014;12(1):e11463. https://doi.org/10.5812/ijem.11463 PMid:24696693 PMCid:PMC3969003

5. Pasieka JL. Anaplastic cancer, lymphoma and metastasis of the thyroid gland. Surg Oncol Clin North Am. 1998;7(4):707-20. https://doi.org/10.1016/S1055-3207(18)30241-2

6. Singer JA. Primary lymphoma of the thyroid. Am Surg 1998;64(4):334-7. PMid:9544144

7. Pedersen RK, Pedersen NT. Primary non-Hodgkin's lymphoma of the thyroid gland: a population based study. Histopathology 1996;28(1):25-32. https://doi.org/10.1046/j.1365-2559.1996.268311.x

8. Sarinah B, Hisham AN. Primary lymphoma of the thyroid: diagnostic and therapeutic considerations. Asian J Surg 2010;33(1):20-4. https://doi.org/10.1016/S1015-9584(10)60004-8

9. Katna R, Shet T, Sengar M, Menon H, Laskar S, Prabhash K, et al. Clinicopathologic study and outcome analysis of thyroid lymphomas: experience from a tertiary cancer center. Head Neck 2013;35(2):165-71. https://doi.org/10.1002/hed.22928 PMid:22368156

10. Watanabe N, Narimatsu H, Noh JY, Kunii Y, Mukasa K, Matsumoto M, et al. Rituximab-including combined modality treatment for primary thyroid lymphoma: an effective regimen for elderly patients. Thyroid 2014;24(6):994-9. https://doi.org/10.1089/thy.2013.0523 PMid:24547778 PMCid:PMC4046220

$\diamond \diamond \diamond \diamond \diamond \diamond \diamond$

http://www.ejgm.co.uk 